\title{
Pandemic and Panic: Negative Emotion of Chinese College Students Caused by News During the Outbreak of COVID-19 Pandemic
}

\author{
Jiajing Sun \\ Department of English and International Studies, China Foreign Affairs University, Beijing, 100037, China \\ 18040554721@163.com
}

\begin{abstract}
The COVID-19 pandemic which was outbreak in 2020 forced people to quarantine at home and only rely on news to get information. As a result, news strongly influenced people's opinions and mental health. College students, the future of China, might be influenced by negative news. This work uses online survey and interview to discuss whether the duration of Chinese college students to pandemic news would increase and whether the pandemic news would be positively correlated with their depression. The results give positive solution to both two hypothesis. The findings suggest that during public crisis, the government should closely monitor students mental health and adjust correlated policy in time.
\end{abstract}

Keywords: News media, mental health, psychological distress, COVID-19 Pandemic, Chinese college students.

\section{INTRODUCTION}

The year 2020 has witnessed a milestone in international relationships. Due to the unexpected outbreak of the COVID-19 pandemic, people are forced to quarantine themselves at home and could only rely on information released by social media. As a result, various news, be it truths or rumors, has strongly influenced people's opinions and furthermore, news strongly influence people's mental health and even influence people's physical health.

In China, college students are the future. During the pandemic, many college students mental health was not stable and needed help. News, as one of the main influence factors, might impact students minds. This study try to find the relationship between news about public health crisis and Chinese students mental health and try to give some suggestions for the future.

\section{LITERATURE REVIEW}

The changing of people's mental health during epidemic has been researched by many scholars. According to Wang, at the beginning of the outbreak of COVID-19 in China, more than half of the interviewees thought their psychological impact rate was moderate-tosevere, and about one-third of them were tested with moderate-to-severe anxiety [1]. Middle aged participants and senior citizens presented the highest CPDI scores (a psychological test) which can show they are the most anxious ones. [2]. For middle aged participants, they always get latest information from social media. Because of writing techniques, the information from social media can always make them feel stressed and anxious [3].

People's mental health is mainly influenced by risk perception. When the risk perception rate is high, it is more possible for people to feel negative emotions. News reporting negative information is closely related with risk perception. If people read more news about public health crisis, they are more likely to feel depressed and their risk perception are more likely to be high[4]. At the same time, the amount and content of such news is closely related with risk perception. According to Holman's team's research, the overly emotional news (for example graphic imagery) is related to readers' higher stress levels [5]. Finally, the duration of news can also be a reason for the audience's risk perception. The study from Wu's team found that if people read pandemic news for a long time, they were more possible to feel depression. What's more, risk perception is one of the medias in the relationship between them [6].

During an epidemic, people always watch entertainment to escape from depressive moods. However, reading news programming may intensify negative moods [7]. News agencies post tons of news to their audiences. These news were originally used to 
The questionnaire includes 11 questions in total, five for basic information and six for the survey. The questions for basic information included the participants' gender, permanent address and location of their universities. Questions for basic information can ensure the validity of the survey.

Questions for the survey included the duration of attention to the news, the duration of attention to pandemic news, the access to news, the emotion during the pandemic and the relation between pandemic news and emotions. From these perspectives, we can better explore the relationship between news and students' emotion.

The questionnaire is as follows:

remind people to prevent COVID-19. But sometimes news not only bring information but also negative emotions. Studies reported that news about public crisis increased the possibility of people feeling negative emotions. Olagoke's team's research which was posted in 2020 shows that reading pandemic news was linked with vulnerability to the pandemic. This might be exposed as depression and other negative feelings [8]. In the USA, greater COVID-19 media consumption is associated with greater negative emotions such as psychological distress [9]. Overall, reading news might influence readers' moods during a crisis.

Based on the previous studies mentioned above, this article posts following hypotheses:

H1: The duration of attention to pandemic news will increase during the pandemic.

$\mathrm{H} 2$ : The pandemic news will be positively correlated with college students' depression.

\section{Methods}

To prove the hypothesis, this study uses an online survey (in Mandarin and English) with Wenjuan.com. The survey posted the questionnaires on April 27, 2021, through WeChat and Weibo. Until April 30, 2021, 1023 participants completed the questionnaires. All participants agreed to participate in the study and they were informed about the purpose of the study. Among all participants, $63 \%(\mathrm{n}=644)$ were males and $37 \%(\mathrm{n}=$ 378) were females.

Pandemic and Panic: Negative Emotion of Chinese College Students Caused by News During the Outbreak of COVID-19

1. I am a Chinese university student during the pandemic?

yes

no

2. Your gender

male

female

others

3. The city you lived in most of last year province

city
4. Is this the same city as your university location? yes

no

5、 the location of your university

province

city

6. I follow the news

$24 / 7$

sometimes

never

7. The main ways I follow the news are (check all that apply)

Weibo

Wechat

newspaper

TV

talk to friends

talk to family

others

8. I followed the news during the pandemic:

more

the same amount

less

never

9. I felt the following during the pandemic (check all that apply)

depressed

anxious

sadness

anger

panic

bored

stressed

lonely

happy

hopeful

tired

other

10. News reports during the epidemic will greatly affect my mental state

1-5 means from strongly disagree to strongly agree, your state is

11. Share how news reports affected you. Please tell a story.

\section{FINDINGS}

In people's general idea, college students do not always follow news. However, the truth comes the opposite. Figure 1 shows that following news is quite popular on Chinese campus. $98.6 \%$ of the participants sometimes or always followed the news, and the participants who never follow news were only $1.4 \%$. The college students followed news in various ways. According to Figure 2, 69.4\% of the participants followed the news from Wechat and $49.6 \%$ from Weibo. 
Figure 1 The frequency of Chinese college students reading news

These are the two major social media platforms in China. The traditional ways such as TV and newspapers were only used by approximately a quarter of the participants.

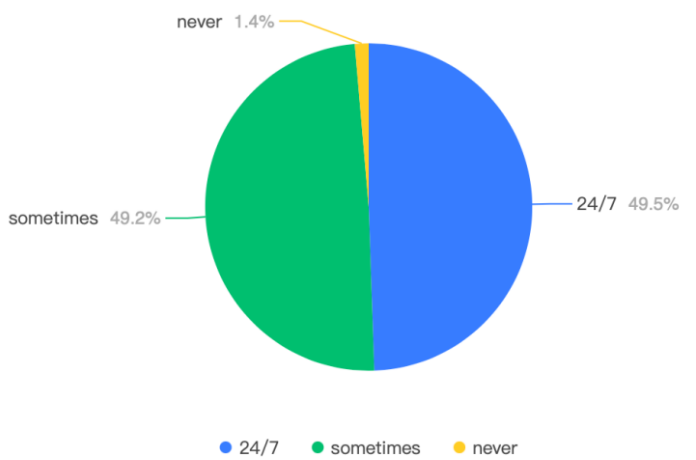

Figure 1 The frequency of Chinese college students reading news

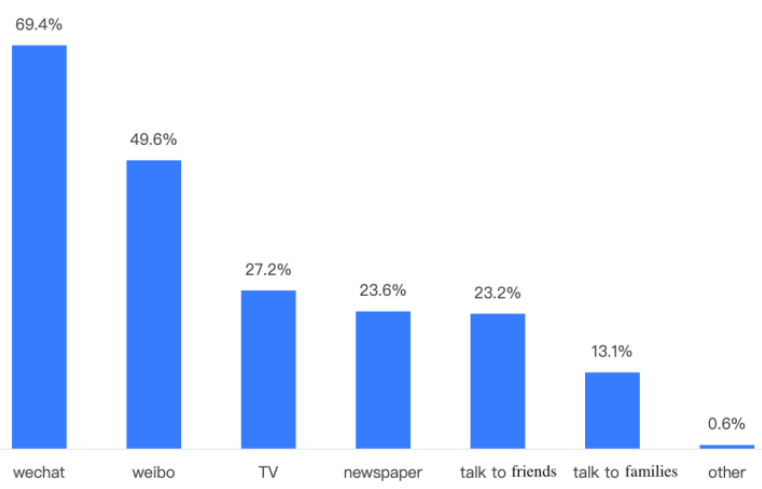

Figure 2 The ways students read news

There was a positive relation between the pandemic news and the negative emotions of college students in China. Figure 3 shows that during the pandemic, college students read news more frequently and spent more time. $48.3 \%$ of the participants followed news more frequently which was almost half, while $34.8 \%$ of the participants followed the news as before and $16.4 \%$ of the participants followed the news even less. According to Figure 4, most of the participants had negative feelings during the pandemic. The negative feelings, for example anger, anxious, sadness, were higher than the positive ones (hopeful, happy), ranging from a low of $20.9 \%$ to a high of $34.7 \%$, with depressed the outlier at a low $9 \%$. The participants who chose anger or sadness were double of those who chose hopeful or happy.

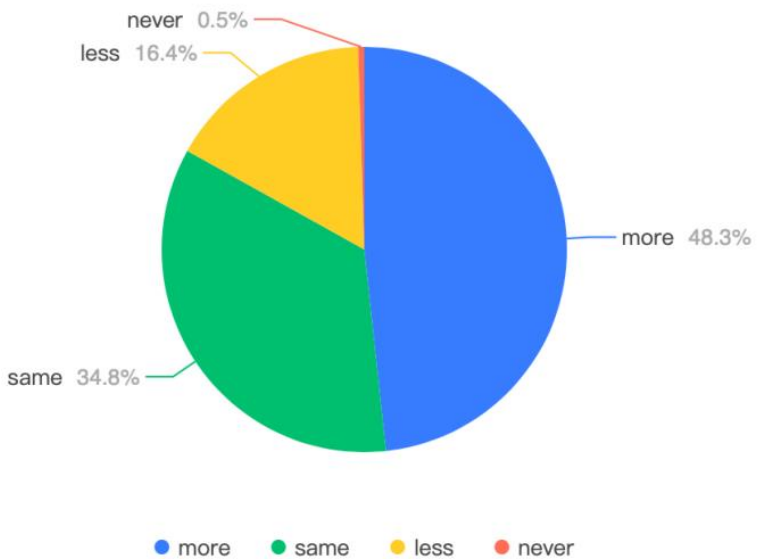

Figure 3 Changes in news reading frequency
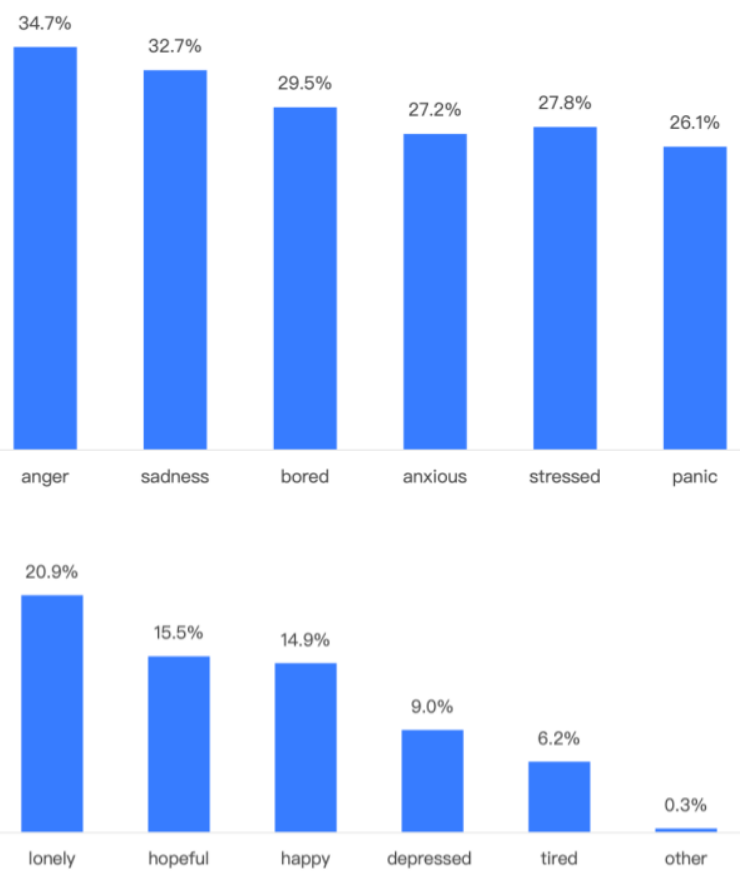

Figure 4 How did participants feel during the pandemic

As shown in Figure 5, 87.5\% of the college students thought news influenced or strongly influenced their emotions, while the opposite came with the data that only $1.6 \%$ of the participants totally disagreed that news would influence their emotions. In general, there was a close relationship between pandemic news and negative emotions. When the students followed more pandemic news, it would be easier for them to feel negative emotions. 


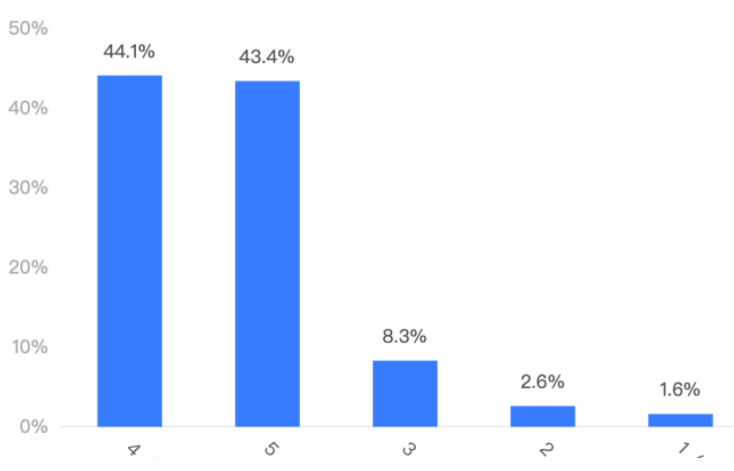

Figure 5 The relation between pandemic news and negative emotions

In the survey, some of the participants shared their stories about how news reports affected their emotions. During the pandemic, some of the students tried to find amusing information online to become more positive. But at that time, this seemed to be impossible. Whenever they watched the news on social media, they would see the news about COVID-19 pandemic which would give them negative emotions. Especially when they heard the news about death of famous people, they would feel upset and scared.

Also, they would worry about their safety and their future. When they watched news, they would feel anxious for they might suffer from the illness as well. Finally, when their friends or families or even strangers were in high-risk areas such as Wuhan, the students would worry about their safety and made them feel negative emotions.

All the data above proved the two hypotheses are true. During the pandemic, college students read news more frequently and the pandemic news, especially the negative ones, had a positive relationship with students' negative emotions.

\section{CONCLUSION}

The researches about the mental health of college students, for example, why so many students have mental health problems and why so many students choose suicide, are popular these days. Researchers not only want to analyze what are the mental health problems of college students but also why they have such problems. By analyzing these questions, the researchers can give more useful suggestions to solve the problems and help more students.

Moreover, it is hard to say human will not face another similar crisis in the future. Only when we sum up the experience, we can know how to deal with such situation and we will not fear and keep calm if another crisis come.

The results of this study give suggestion in order to reducing public's depression level during a health crisis and in other emergencies in the future. Firstly, during a pandemic, news agencies should report more positive information to release people's stress. One of the most useful ways is to increase pleasurable experiences [10]. Concerning college students, the government should post more positive information on Wechat or Weibo and release in a more fashionable way. Secondly, the government should encourage students do not watch the news so frequently. During the pandemic, the news about death and the data must be reported and will occupy a large part of them. However, this does not mean people should always follow the news. The students should be encouraged to take focus on other things for distraction.

This study still has some problems. If the study was done during the peak of the pandemic, the data would be more convincing and the participants would remember more details of their feelings. If other scholars want to analyze similar topics in the future, they can further analyze the difference between students from different locations. They can trace the emotions of students from the beginning of a crisis and analyze the changes of college students emotion during a pandemic or other crisis.

\section{REFERENCES}

[1]. Cheng, M., \& Wang, W. (2011). Theories and effects of China's international communication. Peking University press.

[2]. Qiu, J., Shen, B., Zhao, M., Wang, Z., Xie, B., \& $\mathrm{Xu}, \mathrm{Y}$. (2020). A nationwide survey of psychological distress among Chinese people in the COVID-19 epidemic: Implications and policy recommendations. General Psychiatry, 33(2), e100213. https://doi.org/10.1136/gpsych-2020100213

[3]. Cheng Cheng, L. B., Huang Jun. (2014). Psychological Health Diathesis Assessment System: A Nationwide Survey of Resilient Trait Scale for Chinese Adults. Studies of Psychology and Behavior, 12(6), 735-742.

[4]. Ding, Y., Xu, J., Huang, S., Li, P., Lu, C., \& Xie, S. (2020). Risk Perception and Depression in Public Health Crises: Evidence from the COVID-19 Crisis in China. International Journal of Environmental Research and Public Health, 17(16), 5728. https://doi.org/10.3390/ijerph17165728

[5]. Holman, E. A., Garfin, D. R., Lubens, P., \& Silver, R. C. (2020). Media Exposure to Collective Trauma, Mental Health, and Functioning: Does It Matter What You See? Clinical Psychological Science, $\quad 8(1)$, 111-124. https://doi.org/10.1177/2167702619858300

[6]. Wu, L., Li, X., \& Lyu, H. (2021). The Relationship Between the Duration of Attention to Pandemic News and Depression During the Outbreak of Coronavirus Disease 2019: The Roles of Risk 
Perception and Future Time Perspective. Frontiers in Psychology, 12, 564284. https://doi.org/10.3389/fpsyg.2021.564284

[7]. Potts, R., \& Sanchez, D. (1994). Television viewing and depression: No news is good news. Journal of Broadcasting \& Electronic Media, 38(1), 79-90. https://doi.org/10.1080/08838159409364247

[8]. Olagoke, A. A., Olagoke, O. O., \& Hughes, A. M. (2020). Exposure to coronavirus news on mainstream media: The role of risk perceptions and depression. British Journal of Health Psychology, 25(4), 865-874. https://doi.org/10.1111/bjhp.12427

[9]. Stainback, K., Hearne, B. N., \& Trieu, M. M. (2020). COVID-19 and the 24/7 News Cycle: Does COVID-19 News Exposure Affect Mental Health? Socius: Sociological Research for a Dynamic World, 6, 237802312096933. https://doi.org/10.1177/2378023120969339

[10].Beckham, E. E., \& Adams, R. L. (1984). Coping behavior in depression: Report on a new scale. Behaviour Research and Therapy, 22(1), 71-75. https://doi.org/10.1016/0005-7967(84)90034-2 